\title{
-
}

\section{Destabilization of Heterologous Proteins Mediated by the GSK3 $\beta$ Phosphorylation Domain of the $\beta$-Catenin Protein}

\author{
Yuhan Kong ${ }^{a, b}$ Hongyu Zhang ${ }^{a, b} \quad$ Xian Chen ${ }^{b, c}$ Wenwen Zhang ${ }^{b, c}$ Chen Zhao ${ }^{b, d}$ \\ Ning Wang ${ }^{b, d}$ Ningning W $u^{b, c}$ Yunfeng He $e^{a, b}$ Guoxin Nan ${ }^{b, e}$ Hongmei Zhang ${ }^{b, c}$ \\ Sheng Wen ${ }^{b, e}$ Fang Deng ${ }^{b, d}$ Zhan Liao ${ }^{b, f} \quad$ Di Wu $^{b}$ Junhui Zhang ${ }^{a, b} \quad$ Xinyue Qin ${ }^{a}$ \\ Rex C. Haydon ${ }^{b}$ Hue H. Luu ${ }^{b}$ Tong-Chuan Heb,ce Lan Zhou b,c \\ aThe First Affiliated Hospital, Chongqing Medical University, Chongqing, China; ${ }^{\circ}$ Molecular Oncology \\ Laboratory, Department of Orthopaedic Surgery, The University of Chicago Medical Center, Chicago, \\ IL, USA; 'Ministry of Education Key Laboratory of Diagnostic Medicine, Chongqing Medical University, \\ dDepartments of Cell Biology, Clinical Hematology, and Oncology, Third Military Medical University, \\ eStem Cell Biology and Therapy Laboratory, Ministry of Education Key Laboratory for Pediatrics, The \\ Children's Hospital of Chongqing Medical University, Chongqing, fDepartment of Orthopaedic Surgery, \\ Xiang-Ya Hospital of Central South University, Changsha, China
}

\section{Key Words}

$\beta$-catenin - Wnt signal • Human cancer - Protein degradation • Green fluorescent protein • Destabilized GFP • Chimeric proteins

\footnotetext{
Abstract

Background and Aims: Wnt/ $\beta$-catenin signaling plays important roles in development and cellular processes. The hallmark of canonical Wnt signaling activation is the stabilization of $\beta$-catenin protein in cytoplasm and/or nucleus. The stability of $\beta$-catenin is the key to its biological functions and is controlled by the phosphorylation of its amino-terminal degradation domain. Aberrant activation of $\beta$-catenin signaling has been implicated in the development of human cancers. It has been recently suggested that GSK3 $\beta$ may play an essential role in regulating global protein turnover. Here, we investigate if the GSK3 $\beta$ phosphorylation sitecontaining degradation domain of $\beta$-catenin is sufficient to destabilize heterologous proteins. Methods and Results: We engineer chimeric proteins by fusing $\beta$-catenin degradation domain at the $\mathrm{N}$ - and/or C-termini of the enhanced green fluorescent protein (eGFP). In both transient and stable expression experiments, the chimeric GFP proteins exhibit a significantly decreased stability, which can be effectively antagonized by lithium and Wnt1. An activating mutation in the destruction domain significantly stabilizes the fusion protein. Furthermore, GSK3 inhibitor SB-216763 effectively increases the GFP signal of the fusion protein. Conversely, the inhibition of Wnt signaling with tankyrase inhibitor XAV939 results in a decrease in GFP signal of the fusion proteins, while these small molecules have no significant effects on the mutant destruction domain-GFP fusion protein. Conclusion: Our findings strongly suggest that the 


\section{Cellular Physiology and Biochemistry}

Cell Physiol Biochem 2013;32:1187-1199

\begin{tabular}{l|l}
\hline DOI: $10.1159 / 000354518$ & (C) 2013 S. Karger AG, Basel
\end{tabular}

www.karger.com/cpb

Kong et al.: Degradation Mediated by GSK3 $\beta$ Sites of $\beta$-Catenin

$\beta$-catenin degradation domain may be sufficient to destabilize heterologous proteins in Wnt signaling-dependent manner. It is conceivable that the chimeric GFP proteins may be used as a functional reporter to measure the dynamic status of $\beta$-catenin signaling, and to identify potential anticancer drugs that target $\beta$-catenin signaling.

Copyright (c) 2013 S. Karger AG, Basel

\section{Introduction}

$\beta$-Catenin is an essential signal transducer of the Wnt/Wingless signaling pathway. Many components of this pathway are evolutionarily conserved [1-6]. In normal and unstimulated cells, the majority of $\beta$-catenin protein is present in cell-cell junctions with very little in cytoplasmic or nuclear fractions, due to the rapid degradation of the $\beta$-catenin protein. Wnts initiate the signaling pathway by binding to frizzled receptors, leading to phosphorylation of the dishevelled protein, which, through its association with Axin and APC, prevents GSK3 $\beta$ from phosphorylating $\beta$-catenin. Unphosphorylated $\beta$-catenin is stabilized by escaping recognition by $\beta$-TrCP. It eventually translocates to the nucleus where it engages transcription factors LEF/Tcf-4 to regulate expression of downstream genes, such as c-Myc and cyclin D1 [7-10]. The $\beta$-catenin activity is negatively regulated by many factors, including Tcf-1 [11], Groucho [12], ICAT [13], Idax [14], Duplin [15], Axam [16], presenilin 1 [17], Brg1 [18], HBP1 [19], and Suppressor of fused [20], indicating that $\beta$-catenin signaling is tightly regulated in normal cells $[5,6]$.

Deregulation of $\beta$-catenin signaling may play an important role in tumorigenesis $[4$, $5,21]$. The involvement of $\beta$-catenin in tumorigenesis was first established in colorectal cancer, where $\beta$-catenin was found to form a complex with APC $[22,23]$. The importance of $\beta$-catenin in regulating cell proliferation has been further highlighted by the discovery of oncogenic mutations of $\beta$-catenin in colon cancers containing wild-type APC [24-26]. Mutant $\beta$-catenin protein becomes stable by bypassing APC-targeted degradation. Moreover, $\beta$-catenin mutations have been uncovered in a variety of human tumors [27]. A mutation of Axin was reported in hepatocellular carcinoma [28]. Oncogenic forms of $\beta$-catenin have been shown to induce tumor formation in transgenic animals, whereas mutations in $\beta$-catenin gene have been frequently uncovered in tumors induced by either carcinogens or activated oncogenes [29-31]. Collectively these genetic data suggest that deregulation of $\beta$-catenin signaling may be involved in the development of a broad range of human malignancies.

Stabilization of $\beta$-catenin protein is the key to its activation. Identification of oncogenic mutations in the GSK3 $\beta$ phosphorylation sites of the $\beta$-catenin degradation domain has suggested that down-regulation of GSK3 $\beta$ activity and concomitant stabilization of $\beta$-catenin may be critical to the activation of $\beta$-catenin signaling [27]. Traditionally, Wnt $/ \beta$-catenin activity is measured by using luciferase or GFP reporters driven by Tcf/Lef-binding sites. However, these types of reporters only monitor the downstream events of Wnt/ $\beta$-catenin. A recent report suggests that GSK3 $\beta$ may play an essential role in regulating global protein turnover [32]. Here we investigate the potential effect of the $\beta$-catenin degradation domain (bcd) on the stability of heterologous proteins. When the bcd is fused with GFP at its aminoand/or carboxyl-termini, resulting in $\beta$-catenin destabilized GFPs (bcdGFPs), we find that these fusion proteins exhibit a markedly reduced stability. However, the fusion proteins can be significantly stabilized by lithium and Wnt1. An activating mutation S33P in the destruction domain significantly stabilizes the fusion protein. Furthermore, GSK3 inhibitor SB-216763 [33] effectively increases GFP signal of the fusion protein. Conversely, an inhibition of Wnt signaling with tankyrase inhibitor XAV939 [34] results in a decrease in GFP signal of the fusion proteins. These results strongly suggest that $\beta$-catenin degradation domain may be sufficient to destabilize heterologous proteins in a Wnt signaling-dependent manner. It is conceivable that the chimeric GFP proteins may be used as a functional reporter to measure the dynamic status of $\beta$-catenin signaling, and to identify potential anticancer drugs that target $\beta$-catenin signaling. 


\section{Cellular Physiology and Biochemistry}

Cell Physiol Biochem 2013;32:1187-1199

\begin{tabular}{l|l}
\hline DOI: $10.1159 / 000354518$ & (c) 2013 S. Karger AG, Basel
\end{tabular}

www.karger.com/cpb

Kong et al.: Degradation Mediated by GSK3 $\beta$ Sites of $\beta$-Catenin

\section{Materials and Methods}

Cell Culture and Chemicals

HEK 293 cells and human colon cancer line HCT116 were obtained from the ATCC (Manassas, VA). 293 cells were maintained in complete DMEM supplemented with 10\% FBS (Mediatech, Herndon, VA), 100 units of penicillin, and $100 \mu \mathrm{g}$ of streptomycin at $37^{\circ} \mathrm{C}$ in $5 \% \mathrm{CO}_{2}$. HCT116 cells were maintained in complete McCoy's 5A medium supplemented with 10\% FBS, 100 units of penicillin, and $100 \mu \mathrm{g}$ of streptomycin at $37^{\circ} \mathrm{C}$ in $5 \% \mathrm{CO}_{2}$. GSK inhibitor SB-216763 was obtained from ENZO Life Sciences (Farmingdale, New York, USA). TNKS inhibitor XAV939 was purchased from R \& D Systems (Minneapolis, MN USA). Unless indicated otherwise, all chemicals were purchased from Sigma-Aldrich (St. Louis, MO).

Construction of $\beta$-Catenin Destabilized Green Fluorescent Proteins (bcdGFPs)

The degradation domain of wild-type human $\beta$-catenin was PCR amplified using the following oligonucleotides: 5'-CGGGGTACCATGGGCATGGCTACTCAAG CTGATTT-3' and 5'-CGCGGATCCATTGCATACTGTCCATCAATATC-3'. The amplified fragment was cloned, in-frame with respect to the GFP coding sequence, into the Kpn I and Bam HI sites of pEGFP-N1 (CLONTECH, Palo Alto, CA), resulting fusion protein vector pbcdGFP1 that contained a linker sequence: 5'-GAT CCA CCG GTCGCCACC-3'. For the construction of bcdGFP2 fusion protein, the amplified fragment was cloned, in-frame with respect to GFP coding sequence, into Kpn I and Bam HI sites of pEGFP-C1 (CLONTECH). The pbcdGFP2 fusion protein vector also contained a multiple cloning sites-derived linker sequence: 5'-TCCGGACTCAGATCTCGAGCTCAAGCTTC GAATTCTGCAGTCGACGGTACCATGGGC-3'. The pbcdGFP3 was constructed on the base of pbcdGFP1 vector by replacing its BsrGI/Stu I fragment with the corresponding fragment derived from pbcdGFP2. The activating mutant S33P of the N-terminal bcd domain of bcdGFP1, namely mbcdGFP, was generated by using sitedirected mutagenesis. All PCR amplified sequences and cloning junctions were verified by DNA sequencing.

\section{Establishment of Inducible Cell Lines Expressing bcdGFP Fusion Proteins}

The coding regions of bcdGFP fusion proteins were subcloned into THE inducible system previously developed in our laboratory [35]. For a control, EGFP coding sequence was also cloned into the tetracycline inducible system. Details on vector construction are available upon request. Exponentially growing 293 cells were transfected with $1.0 \mu \mathrm{g}$ DNA per $25 \mathrm{~cm}^{2}$ tissue culture flask with Lifectamine (Life Technologies, Gaithersburg, MD). At 24h after transfection, cells were trypsinized and replated into 96-well cell culture plates at multiple dilutions. Stable clones were selected in the presence of G418 at a final concentration of $0.2 \mathrm{mg} / \mathrm{ml}$ for two weeks. Clones derived from single cells were grown up for further characterization.

\section{Western Blotting Analysis}

Western blotting was carried out as previously described [36-42]. Briefly, cleared total cell lysates were subjected to SDS-PAGE. After electrophoresis, proteins were transferred to an Immobilon-P membrane (Millipore) via electroblotting. The membrane was blocked with $5 \%$ nonfat milk in TBST (10mM Tris- $\mathrm{HCl}$, pH8.0, $150 \mathrm{mM} \mathrm{NaCl}, 0.05 \%$ Tween-20) at room temperature for $1 \mathrm{~h}$ and probed with a rabbit anti-GFP antibody (CLONTECH) for $1 \mathrm{~h}$, followed by 30MIN incubation with anti-rabbit IgG-HRP secondary antibody (PIERCE). The presence of GFP protein was detected by using the SuperSignal West Pico Chemiluminescent Substrate kit (PIERCE).

\section{Preparation of Wht-1 Conditioned Medium}

The cDNA encoding mouse Wnt-1 was subcloned into pAdTrack-CMV vector. Recombinant adenovirus expressing Wnt-1 (AdWnt1) was generated as previously described [43-48]. To prepare Wnt-1 conditioned medium (Wnt1-CM), AdWnt1 was used to infect exponentially growing HCT116 cells in $75 \mathrm{~cm}^{2}$ cell culture flasks (MOI = 20) [49]. Adenovirus-containing medium was changed at $6 \mathrm{~h}$ after infection and replaced with $10 \mathrm{ml}$ DMEM per $75 \mathrm{~cm}^{2}$ flask. The Wnt 1 conditioned medium was collected at $24 \mathrm{~h}$ and, after passing through $0.2 \mu \mathrm{m}$ filters, was kept at $-80^{\circ} \mathrm{C}$ in $2.0 \mathrm{ml}$ aliquots.

\section{FACS Analysis}

293-bcdGFP3 and 293-EGFP cells were induced with doxycycline $(1 \mathrm{ng} / \mathrm{ml})$ for $16 \mathrm{~h}$, followed by washing with PBS three times. Cells were collected by trypsinization at 0,24 , and $48 \mathrm{~h}$ after doxcycline 
Fig. 1. (A) Structural representation of EGFP and three bcdGFP fusion proteins. EGFP, a nonfusion control; bcdGFP1, a $\beta$-catenin (aa1-88) fusion protein at the N-terminus of the EGFP; bcdGFP2, a $\beta$-catenin (aa1-88) fusion protein at the C-terminus of the EGFP; bcdGFP3, a $\beta$-catenin (aa1-88) fusion protein at both $\mathrm{N}$ and C-termini of the EGFP; aa, amino acid. (B) Exponentially growing 293 cells were transfected with the expression vectors for EGFP and three bcdGFP fusions. At $24 \mathrm{~h}$ cells were collected, lysed and subjected to Western blotting using a rabbit anti-GFP antibody. Total cell lysate derived from empty vector-transfected cells was used as a control (Lane 5).

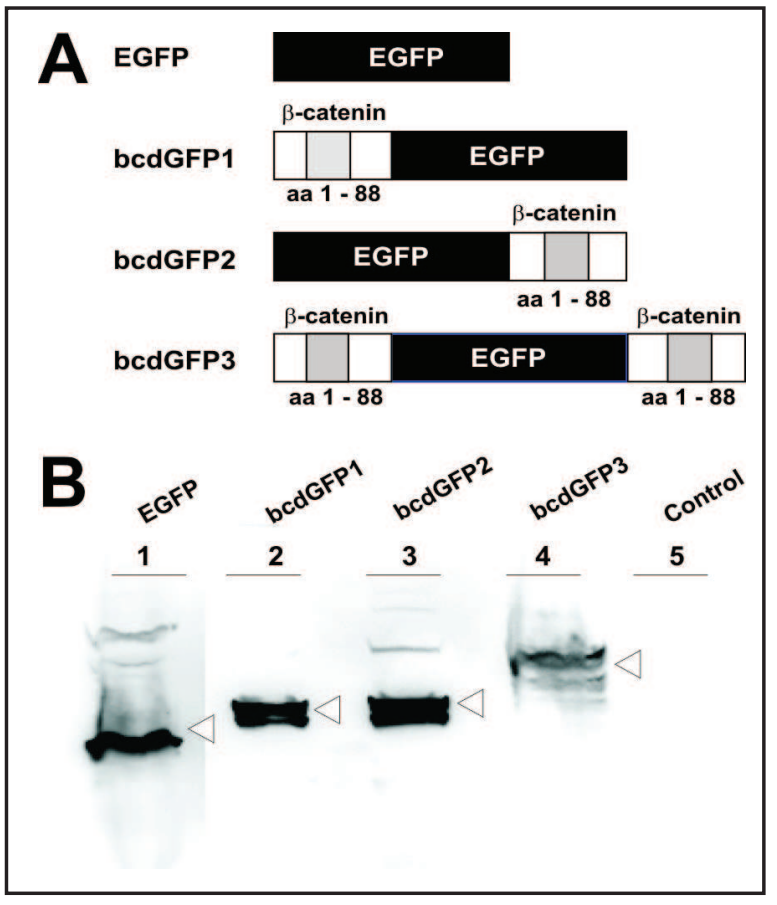

removal, and were resuspended in complete DMEM at $5 \times 10^{5}$ cells $/ \mathrm{ml}$. Cells were subjected to FACScan (Becton Dickinson, San Jose, CA) with the signal gated to measure GFP fluorescence. Signal threshold was determined by using parental 293 cells. Approximately 10,000 cells were analyzed to determine mean fluorescence intensity of each sample. The mean fluorescence intensity of the induced cells at 0 hour after doxycycline removal was used as the $100 \%$ control.

\section{Quantification of GFP Signal Level}

All images with GFP expression were captured and processed with NIH ImageJ software to quantify the amount and intensity of fluorescence and compare levels across different samples as previously described [50]. Briefly, fluorescent images were captured with the fixed exposure time (i.e., 0.25 second) and size (in pixels). Images were converted to 8-bit grayscale format to simplify processing. Because there was mainly one channel of color (green), there was not significant data loss during this conversion. A histogram was then constructed to analyze the distribution of pixel values. This distribution list was then imported into an Excel (Microsoft) spreadsheet, and the pixel value (0-256) was multiplied by the number of pixels in the image that contained that value. The Total Image Value (TIV) was defined as the sum of all the pixel values multiplied by the pixel counts and was directly proportional to the amount of fluorescence. At least 10 randomly selected images were captured and analyzed for each assay conditions. The average TIVs were used for further analysis, including statistical analysis.

\section{Statistical Analysis}

All quantitative experiments were performed in triplicate and/or repeated three times. Data were expressed as mean \pm SD. Statistical significances were determined by one-way analysis of variance and the student's t test. A value of $\mathrm{p}<0.05$ was considered statistically significant.

\section{Results}

\section{Construction of bcdGFP Fusion Proteins}

It is generally assumed that the GSK3 $\beta$ kinase plays an important role in the APC-targeted degradation of $\beta$-catenin through the ubiquitin/proteosome pathway. The degradation process is presumably initiated by GSK3 $\beta$-mediated phosphorylation of the N-terminal 


\section{Cellular Physiology and Biochemistry}

Cell Physiol Biochem 2013;32:1187-1199

\begin{tabular}{l|l}
\hline DOI: $10.1159 / 000354518$ & (c) 2013 S. Karger AG, Basel
\end{tabular}

ublisned ontine: November 14, $2013 \quad$ www.karger.com/cpb

Kong et al.: Degradation Mediated by GSK3 $\beta$ Sites of $\beta$-Catenin

Fig. 2. (A) 293 cells were transfected with vectors expressing EGFP, bcdGFP1, bcdGFP2, and bcdGFP3. At $24 \mathrm{~h}$ after transfection, cyclohemixide (CHX) was added to the transfected cells. GFP intensity was recorded under a fluorescence microscope at $4 \mathrm{~h}$ and $9 \mathrm{~h}$. The untreated cells were used as a control. (B) 293 cells were transfected with vectors expressing EGFP, bcdGFP1, bcdGFP2, and bcdGFP3 as described in (A). At $16 \mathrm{~h}$ cells were treated with $\mathrm{CHX}$ for $4 \mathrm{~h}$, $9 \mathrm{~h}, 14 \mathrm{~h}$ and $24 \mathrm{~h}$ and subjected to flow cytometry. Each assay condition was done in triplicate. \% decrease in GFP signal was calculated by comparing the GFP signal (TIV) with that of respective no-CHX control.

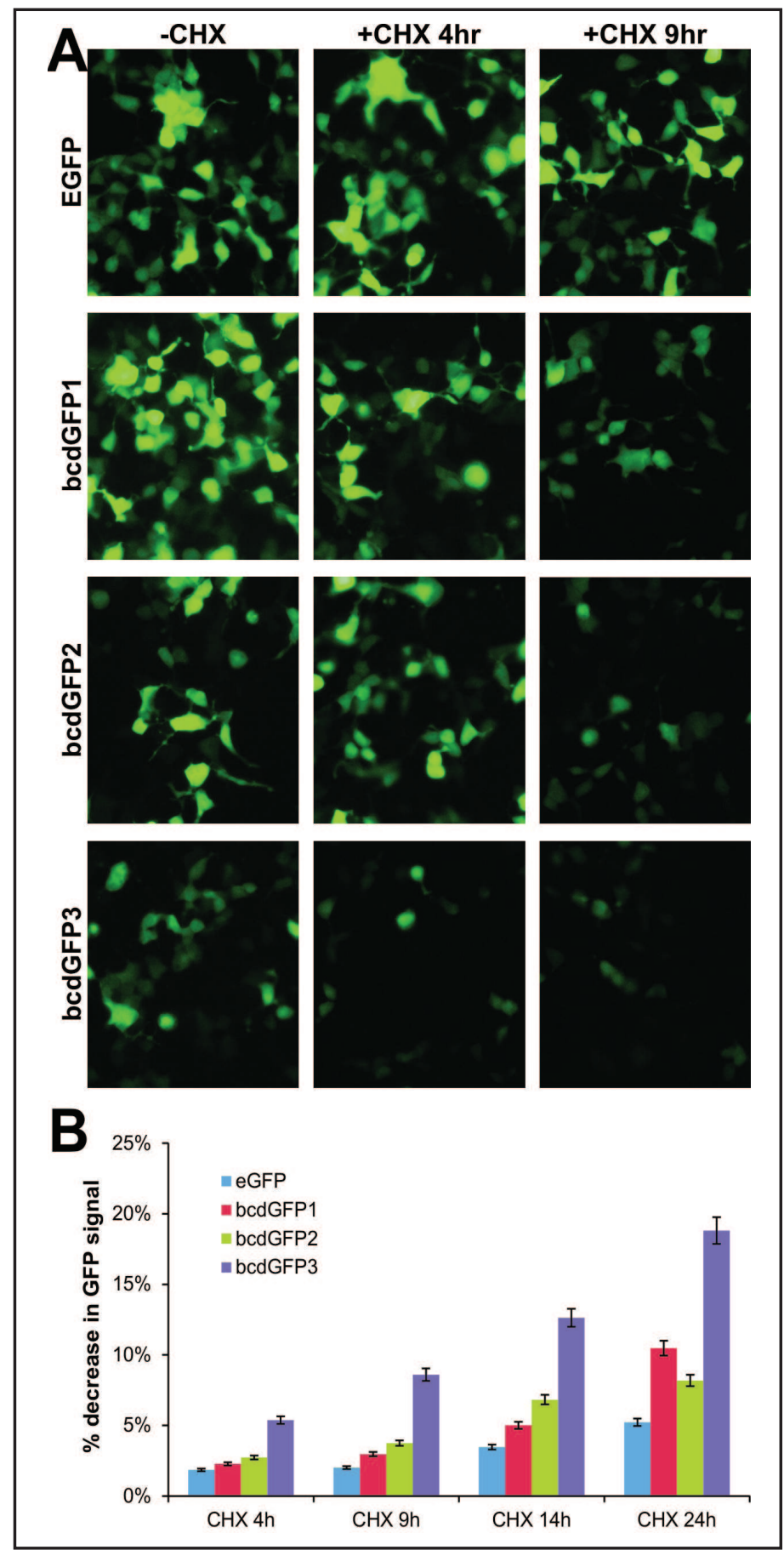

portion of $\beta$-catenin $[27,51]$. As illustrated in Fig. $1 \mathrm{~A}$, we constructed three $\beta$-cateninGFP fusion proteins. Among them, the bcdGFP1 was a chimeric protein with the $\beta$-catenin degradation domain (amino acids 1-88) fused to the N-terminus of EGFP. The bcdGFP2 was a chimeric protein with the presumed degradation domain of $\beta$-catenin fused to the $C$-terminus of EGFP, whereas bcdGFP3 was a fusion of the EGFP flanked with $\beta$-catenin degradation domains. When the constructs were transiently transfected into 293 cells, the expression of bcdGFP fusion proteins was confirmed by Western blotting using an anti-GFP antibody (Fig. 1B). Interestingly, several lower bands were reproducibly observed in bcdGFP3-transfected cell lysate (Fig. 1B, lane 4), which may represent the degraded products of bcdGFP3. 


\section{Cellular Physiology and Biochemistry}

Cell Physiol Biochem 2013;32:1187-1199

\begin{tabular}{l|l}
\hline DOI: $10.1159 / 000354518$ & (c) 2013 S. Karger AG, Basel
\end{tabular}

ublisned ontine: November 14, 2013 www.karger.com/cpb

Kong et al.: Degradation Mediated by GSK3 $\beta$ Sites of $\beta$-Catenin

Fig. 3. (A) Inducible 293 lines expressing EGFP, bcdGFP1, bcdGFP2, and bcdGFP3 were exposed to doxycycline for $24 \mathrm{~h}$. Doxycycline was removed by washing the cells with complete DMEM. GFP intensity was recorded at $24 \mathrm{~h}$ or $48 \mathrm{~h}$ afterwards. Cells constantly exposed to doxycycline were used as a positive control. (B) Cells were induced with doxycycline for $16 \mathrm{~h}$, followed by washing with PBS and adding doxycycline-free complete medium. At the indicated hours after doxycycline removal, cells were collected and subjected to FACS analysis. Each assay condition was done in triplicate. Mean fluorescence signal (TIV) of the induced cells at $0 \mathrm{hr}$ after doxycycline removal was used as the $100 \%$ control.

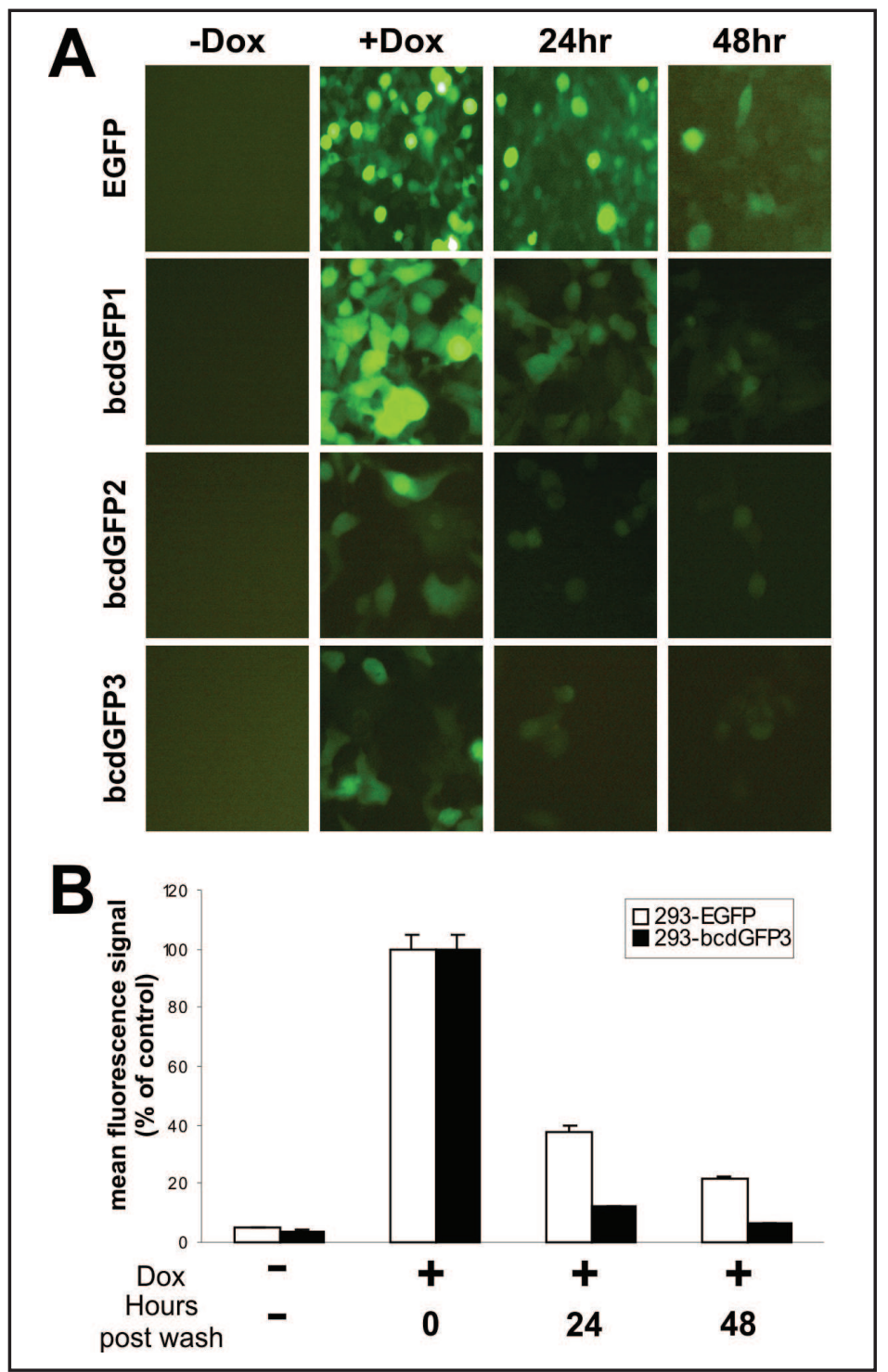

Destabilization of bcdGFP Fusion Proteins

We transfected the bcdGFPs and pEGF-C1 expression vectors into 293 cells. At $24 \mathrm{~h}$ after transfection, protein synthesis inhibitor cycloheximide was added to the medium (100 ng/ml) for $4 \mathrm{~h}$ or $9 \mathrm{~h}$. GFP intensity was evaluated. As shown in Fig. 2A, GFP signal was readily observed in 293 cells transfected with the three fusion constructs and control EGFP vector. However, the cells transfected with bcdGFP2 and bcd-GFP3 constructs exhibited lower level of GFP expression (Fig. 2A, -CHX column). When exposed to cycloheximide, the bcdGFP-transfected cells exhibited a significant decrease in GFP intensity, suggesting that the produced bcdGFP fusion proteins were less stable than control EGFP protein. Further quantitative analysis of GFP signal intensity indicates that bcdGFP3 exhibited the greatest decrease in a time-dependent manner (Fig. 2B).

Establishment of Stable Clones Expressing bcdGFPs in an Inducible Fashion

To further analyze the dynamics of the destabilization effect mediated by $\beta$-catenin degradation domain on these fusion proteins, we subcloned the bcdGFP fusion constructs and the control EGFP into pTHE inducible system [35]. These inducible constructs were transfected into 293 cells, and multiple stable cell lines for each construct were generated and characterized. As shown in Fig. 3A, the background expression of GFP was negligible 


\section{Cellular Physiology and Biochemistry}

Cell Physiol Biochem 2013;32:1187-1199

\begin{tabular}{l|l}
\hline DOI: $10.1159 / 000354518$ & (C) 2013 S. Karger AG, Basel
\end{tabular}

www.karger.com/cpb

Kong et al.: Degradation Mediated by GSK3 $\beta$ Sites of $\beta$-Catenin

in all four inducible lines (Fig. 3A, -Dox column). Upon the addition of doxycycline (1ng/ $\mathrm{ml}$ ), GFP expression was readily detected at $24 \mathrm{~h}$ after induction in all lines (Fig. $3 \mathrm{~A},+$ Dox column). However, when doxycycline was removed at $24 \mathrm{~h}$ of induction, the GFP signals of all fusion constructs became weaker than that of the control EGFP at $24 \mathrm{~h}$ and $48 \mathrm{~h}$ post doxycycline removal (Fig. 3A, $24 \mathrm{~h}$ and $48 \mathrm{~h}$ columns), suggesting that bcdGFP proteins were significantly less stable. Consistent with the earlier findings (Figs. 1B and 3), bcdGFP3 fusion was reproducibly shown to exhibit the most pronounced destabilization effect.

We next carried out quantitative FACS analysis of the stability of bcdGFP3 protein. As shown in Fig. 3B, 293-bcdGFP3 exhibited a significantly decrease in stability. Specifically, at $24 \mathrm{~h}$ after doxycycline removal the mean fluorescence intensity of 293-bcdGFP3 decreased to approximately $12 \%$ of the unwashed control, while the mean fluorescence intensity of 293EGFP only decreased to approximately $37 \%$ of the unwashed control. Similarly, at $48 \mathrm{~h}$ after doxycycline removal, the mean fluorescence intensity of 293-bcdGFP3 almost decreased to the basal level (approximately 6\% of the unwashed control), whereas the 293-EGFP still maintained about $21 \%$ of the mean fluorescence intensity of the control (Fig. 3B). Similar results were also obtained from 293-bcdGFP1 and 293-bcdGFP2 lines, although the decrease of fluorescence intensity in these lines was less pronounced than that of 293-bcdGFP3 line (data not shown). Taken together, these results strongly suggest that the chimeric GFP proteins may be destabilized by $\beta$-catenin destruction domain.

Destabilization Mediated by the $\beta$-Catenin Degradation Domain Can Be Antagonized by Lithium and Wnt1

Lithium is a commonly-used Wnt surrogate, which presumably mimics the Wnt signal by inhibiting GSK3 $\beta$ activity $[52,53]$. We tested the effect of lithium on the stability of bcdGFP fusion proteins. As shown in Fig. 4A, a significant increase in GFP intensity was observed in bcdGFP lines (especially for bcdGFP2 and bcdGFP3 cells) in the presence of both doxycycline $(1 \mathrm{ng} / \mathrm{ml})$ and lithium chloride $(30 \mathrm{mM})$ for $24 \mathrm{~h}$ (Fig. $4 \mathrm{~A}$, right column), whereas no significant increase in GFP intensity for the EGFP control line was observed under the same conditions, suggesting that the destabilization effect of $\beta$-catenin-GFP fusions can be antagonized by lithium.

To produce biologically active Wnt 1 protein, we generated a recombinant adenoviral vector, AdWnt1, which constitutively expresses mouse Wnt1 under the control of the CMV promoter. AdWnt1-mediated Wnt1 expression was readily detected by Western blotting analysis [49] (data not shown). We prepared Wnt1-conditioned medium (Wnt1-CM) by harvesting the Wnt1-containing medium from AdWnt1-infected HCT116 cells. Wnt1-CM was biologically active as it was shown to effectively activate a Tcf4-responsive reporter [49] (data not shown). To test Wnt1-CM's stabilizing effect on the bcdGFP proteins, bcdGFP3 and control EGFP cells were transiently induced with doxycycline $(1 \mathrm{ng} / \mathrm{ml})$ for $12 \mathrm{~h}$, followed by washing cells with complete DMEM three times. Wnt1-CM was added to the washed cells. GFP signal was recorded at $24 \mathrm{~h}$ and $48 \mathrm{~h}$ after Wnt1-CM stimulation. As shown in Fig. 4B, basal GFP signal was low in both lines (Fig. 4B, -Dox row). Upon addition of doxycycline, GFP intensity was significantly induced in EGFP line, but slightly enhanced in bcdGFP3 line (Fig. 4B, +Dox row). At 48h after doxycycline removal, the induced GFP signal significantly diminished in EGFP line and completely disappeared in bcdGFP3 line (Fig. 4B, Wash 48h row). However, the addition of Wnt1-CM was shown to profoundly increase the stability of GFP signal in bcdGFP3 line, but to exert little effect on the control EGFP line (Fig. 4B, bottom two rows). Similar results were obtained for bcdGFP2 and, to a lesser extent, for bcdGFP1 (data not shown). We further conducted a quantitative analysis of Wnt1-mediated stabilization of bcdGFP proteins using FACS and demonstrated that bcdGFP3 exhibited the highest increase in GFP signal intensity upon Wnt1 stimulation, although all three bcdGFP proteins had significant increases in GFP signal $(p<0.01)$ (Fig. 4C). These findings, together with the results obtained from the lithium study, have demonstrated that $\beta$-catenindestabilized GFP proteins can be stabilized in a Wnt signal-dependent fashion. 


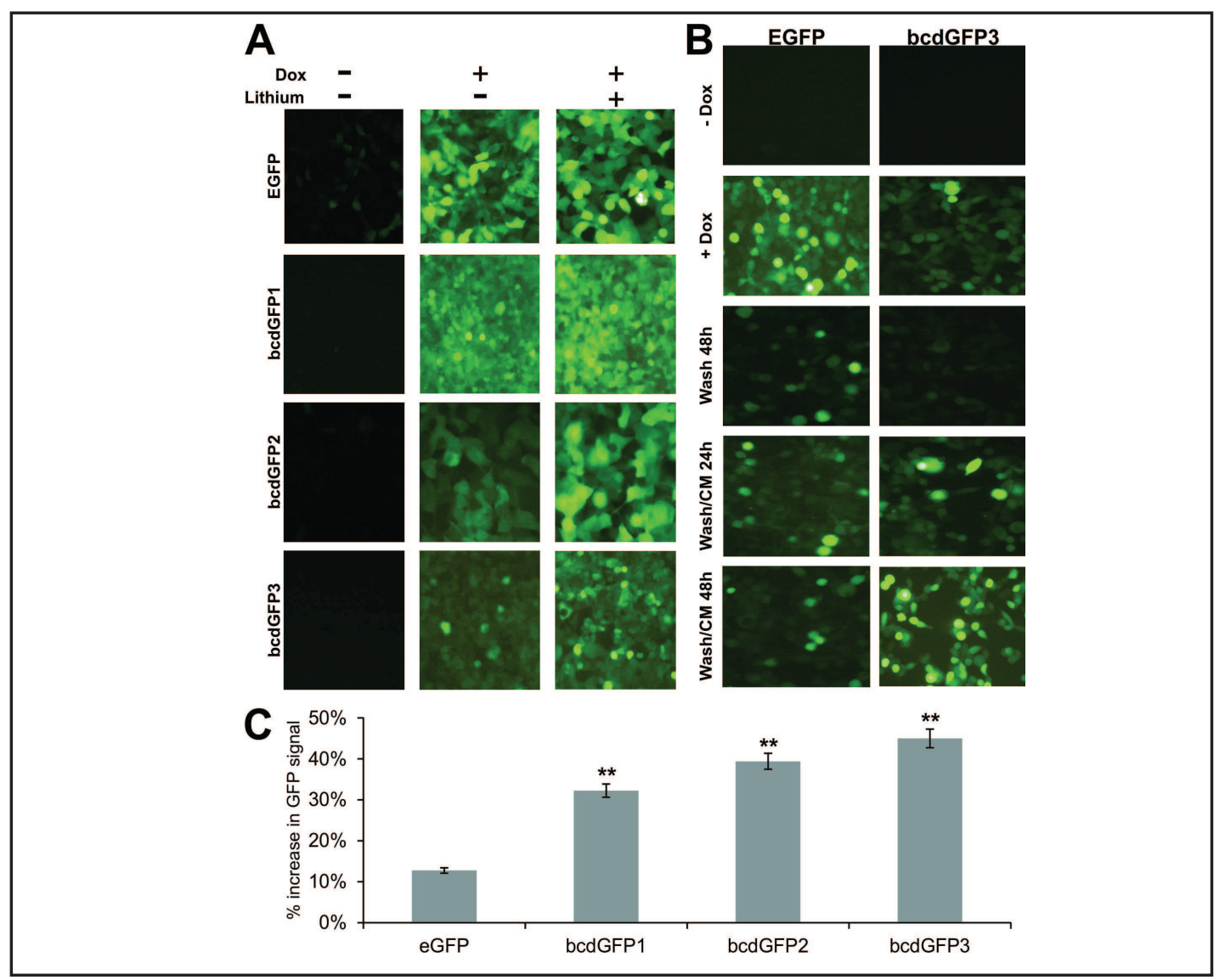

Fig. 4. (A) The bcdGFP1, bcdGFP2, bcdGFP3, and EGFP lines were plated in 12-well cell culture plates, and were induced with doxycycline in the presence or absence of lithium chloride. At 24h GFP expression was recorded. (B) Both bcdGFP3 and EGFP cells were plated in 12-well plates. Cells were transiently induced by doxycycline for $12 \mathrm{~h}$. After washing the cells, Wnt1-CM was added to the cells. GFP signal was recorded at $24 \mathrm{~h}$ and $48 \mathrm{~h}$ after Wnt 1 stimulation. Controls were the un-induced and the transiently induced at 48 hours after doxycycline removal (Wash 48h). (C) 293 cells were transfected with vectors expressing EGFP, bcdGFP1, bcdGFP2, and bcdGFP3 as described in Fig. 4A. At 16h cells were washed and treated with Wnt1CM or GFP-CM for additional 24h. Cells were collected and subjected to flow cytometry. Each assay condition was done in triplicate. \% increase in GFP signal was calculated by comparing the mean GFP TIV with that of respective GFP-CM treatment control. “**”, $p<0.01$.

\section{Small Molecules That Modulate Wnt/ß-Catenin Pathway Can Affect the Stability of bcdGFP} Proteins

To further demonstrate that the instability of bcdGFP proteins is mediated by $\beta$-catenin destruction domain, we constructed an activating mutant mbcdGFP, which harbors S33P mutation at the bcd domain, through site-directed mutagenesis (Fig. 5A). The mutant bcd was shown to increase the stability of GFP signal, when compared with that of bcdGFP3's (Fig. 5B, a \& b vs. c \& d). Using this mutant and bcdGFP3, we tested the effects of the commonlyused GSK3 inhibitor SB-216763 [33] and Wnt signal/tankyrase inhibitor XAV939 [34] on the GFP stability. When bcdGFP3-expressing cells were treated with SB-216763, there was an apparent increase in GFP signal intensity/positivity, while no significant changes were observed in mbcdGFP-expressing cells (Fig. 5C, a vs. b and d vs. e), suggesting that the GSK3 inhibitor may mimic Wnt activation. Conversely, an inhibition of Wnt signaling with tankyrase inhibitor XAV939 resulted in a decrease in GFP signal in bcdGFP3-expressing cells 


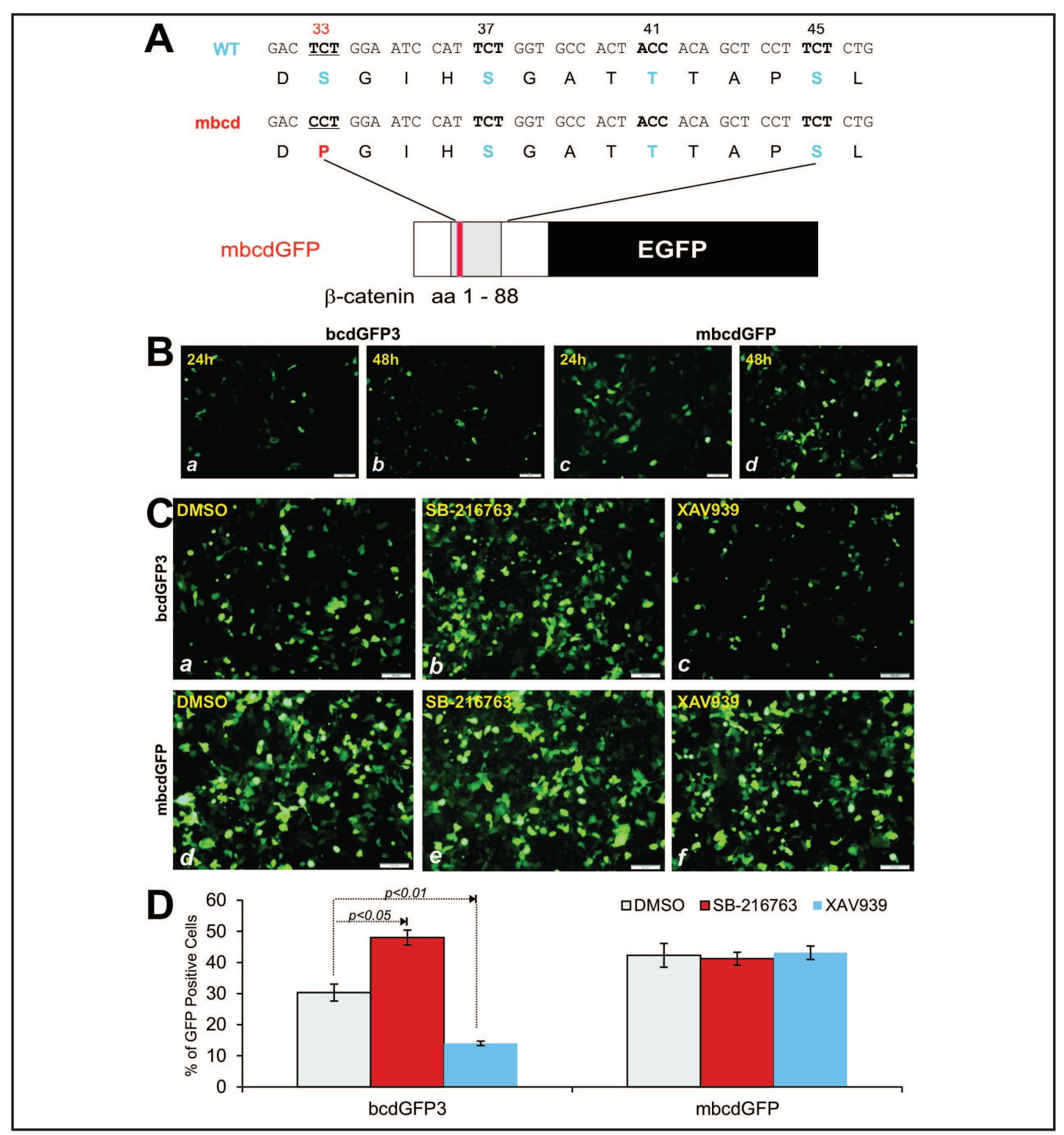

Fig. 5. (A) Schematic representation of the S33P mutant bcdGFP construct. (B) 293 cells were transfected with bcdGFP3 or mbcdGFP plasmid DNA. GFP signal was recorded at $24 \mathrm{~h}$ and $48 \mathrm{~h}$ after transfection. Representative results are shown. (C) 293 cells were transfected with bcdGFP3 or mbcdGFP expression vector for $16 \mathrm{~h}$ and treated cells with SB-216763 $(10 \mu \mathrm{M})$, XAV939 $(2.5 \mu \mathrm{M})$ or DMSO. At $24 \mathrm{~h}$ GFP signal was recorded. Each assay condition was done in duplicate. Representative results are shown. (D) Flow cytometric analysis of SB-216763 or XAV939-treated cells. 293 cells were transfected and treated with SB-216763 or XAV939 as described in (C). At $24 \mathrm{~h}$ cells were collected and subjected to flow cytometry to determine GFP positive cells above the fixed threshold. Each assay condition was done in triplicate.

but not in mbcdGFP cells (Fig. 5D, a vs. c and d vs. f), consistent with the presumed function of bcdGFP3 as Wnt signaling reporter. Lastly, we performed a quantitative analysis on these small molecules' effect on bcdGFP proteins. As shown in Fig. 5D, SB-216763 significantly increased the GFP signal of bcdGFP3 $(p<0.05)$ while XAV939 drastically inhibited the GFP signal of bcdGFP3 $(p<0.01)$. Neither compounds exhibited any significant effect on the GFP signal of mbcdGFP's. 


\section{Cellular Physiology and Biochemistry}

Cell Physiol Biochem 2013;32:1187-1199

\begin{tabular}{l|l}
\hline DOI: $10.1159 / 000354518$ & (C) 2013 S. Karger AG, Basel
\end{tabular}

www.karger.com/cpb

Kong et al.: Degradation Mediated by GSK3 $\beta$ Sites of $\beta$-Catenin

\section{Discussion}

Our findings have demonstrated that the $\mathrm{N}$-terminal degradation domain of $\beta$-catenin can efficiently mediate a destabilization signal for heterologous proteins, such as GFP. The destabilizing effect seems to be the most pronounced in bcdGFP3 and the least in bcdGFP1. Both lithium and Wnt1-CM can effectively antagonize the destabilizing effect and to drastically increase the stability of bcdGFP proteins. Therefore, these bcdGFPs may be used as a biological reporter for $\beta$-catenin signaling, and have at least two important functional and technological ramifications.

First, such destabilized GFP proteins (especially bcdGFP3) can be used as an effective biological reporter to assess the functional status of Wnt signaling or to identify potential upstream factors that can stabilize $\beta$-catenin protein. Such factors may play an important role in the development of human cancers. Cytoplasmic and/or nuclear accumulation or elevation of $\beta$-catenin protein has been detected in a broad range of human tumors $[27,54-$ $56]$. With the exception of colon cancer, molecular and/or genetic causes of the accumulation of $\beta$-catenin is not known since mutations in $\beta$-catenin, APC tumor suppressor, or other negative regulators of the $\beta$-catenin signaling pathway are infrequent in most tumor types.

Secondly, the reported bcdGFP fusions may be used as a functional tool to screen for candidate compounds that can specifically inhibit $\beta$-catenin signaling. Because of the built-in GFP reporter, a high throughput strategy can be devised. Compounds from a combinatorial library can be added to the cells and robotic automation for the GFP signal measurement may be performed. Leading compounds that antagonize Wnt signal and diminish the GFP signal can be selected for further study. Ultimately, this line of investigation may lead to the development of novel and effective anti-cancer agents.

While it remains to be further elucidated if the destruction domain of $\beta$-catenin is a necessary and sufficient measurement of Wnt/ $\beta$-catenin activity, our results have been supported by a recent report from De Robertis' group [32]. They found that Wnt signaling caused the relocalization of cytoplasmic GSK3 to multivesicular endosomes. Cryoimmunoelectron microscopy showed that GSK3 was translocated from cytosol into multivesicular bodies after Wnt pathway activation, whereas Wnt signal transduction was blocked by depletion of Hrs/Vps27 or expression of dominant-negative Vps4, two proteins essential for intralumenal vesicle formation in multivesicular bodies [32]. As approximately $20 \%$ of the human proteome contains multiple putative GSK3 phosphorylation sites, total protein half-life was extended by Wnt treatment or GSK3 inhibition [32]. They in fact showed that the addition of GSK3 phosphorylation sites was sufficient to place the stability of a GFP biosensor under the control of Wnt. They concluded that canonical Wnt signaling sequesters GSK3 inside multivesicular bodies, reducing GSK3 cytosolic levels and extending the halflife of many GSK3 substrates [32]. Our results are consistent with this observation. Thus, bcdGFP fusion proteins may be used as a functional barometer for Wnt/ $\beta$-catenin signaling activity.

\section{Conflict of Interest}

The authors declare no conflict of interest.

\section{Acknowledgements}

The reported work was supported in part by research grants from the National Institutes of Health (CA106569, AT004418, AR50142, and AR054381 to TCH, RCH and HHL), and the 973 Program of Ministry of Science and Technology (MOST) of China (\#2011CB707900 to TCH and LZ). 


\section{Cellular Physiology and Biochemistry}

Cell Physiol Biochem 2013;32:1187-1199

\begin{tabular}{l|l}
\hline DOI: $10.1159 / 000354518$ & (c) 2013 S. Karger AG, Basel
\end{tabular}

www.karger.com/cpb

Kong et al.: Degradation Mediated by GSK3 $\beta$ Sites of $\beta$-Catenin

\section{References}

$>1$

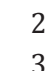

$>3$ 4511.

20 Meng X, Poon R, Zhang X, Cheah A, Ding Q, Hui Cc C, Alman B: Suppressor of fused negatively regulates beta-catenin signaling. J Biol Chem 2001;26:26.

-21 Kinzler KW, Vogelstein B: Lessons from hereditary colorectal cancer. Cell 1996;87:159-170.

22 Rubinfeld B, Souza B, Albert I, Muller O, Chamberlain SH, Masiarz FR, Munemitsu S, Polakis P: Association of the apc gene product with beta-catenin. Science 1993;262:1731-1734.

-23 Su LK, Vogelstein B, Kinzler KW: Association of the apc tumor suppressor protein with catenins. Science 1993;262:1734-1737.

-24 Morin PJ, Sparks AB, Korinek V, Barker N, Clevers H, Vogelstein B, Kinzler KW: Activation of beta-catenin-tcf signaling in colon cancer by mutations in beta-catenin or apc [see comments]. Science 1997;275:17871790.

-25 Rubinfeld B, Robbins P, El-Gamil M, Albert I, Porfiri E, Polakis P: Stabilization of beta-catenin by genetic defects in melanoma cell lines [see comments]. Science 1997;275:1790-1792. 


\section{Cellular Physiology and Biochemistry}

Cell Physiol Biochem 2013;32:1187-1199

\begin{tabular}{l|l}
\hline DOI: $10.1159 / 000354518$ & (C) 2013 S. Karger AG, Basel
\end{tabular} www.karger.com/cpb

Kong et al.: Degradation Mediated by GSK3 $\beta$ Sites of $\beta$-Catenin

26 Sparks AB, Morin PJ, Vogelstein B, Kinzler KW: Mutational analysis of the apc/beta-catenin/tcf pathway in colorectal cancer. Cancer Res 1998;58:1130-1134.

27 Polakis P: Wnt signaling and cancer. Genes Dev 2000;14:1837-1851.

-28 Satoh S, Daigo Y, Furukawa Y, Kato T, Miwa N, Nishiwaki T, Kawasoe T, Ishiguro H, Fujita M, Tokino T, Sasaki Y, Imaoka S, Murata M, Shimano T, Yamaoka Y, Nakamura Y: Axin1 mutations in hepatocellular carcinomas, and growth suppression in cancer cells by virus-mediated transfer of axin1. Nat Genet 2000;24:245-250.

-29 Gat U, DasGupta R, Degenstein L, Fuchs E: De novo hair follicle morphogenesis and hair tumors in mice expressing a truncated beta-catenin in skin. Cell 1998;95:605-614.

-30 Harada N, Tamai Y, Ishikawa T, Sauer B, Takaku K, Oshima M, Taketo MM: Intestinal polyposis in mice with a dominant stable mutation of the beta-catenin gene. Embo J 1999;18:5931-5942.

-31 Tsujiuchi T, Tsutsumi M, Sasaki Y, Murata N, Konishi Y: Mutations of adenomatous polyposis coli and betacatenin genes during progression of lung tumors induced by n-nitrosobis(2-hydroxypropyl)amine in rats. [in process citation]. Cancer Res 2000;60:6611-6616.

-32 Taelman VF, Dobrowolski R, Plouhinec JL, Fuentealba LC, Vorwald PP, Gumper I, Sabatini DD, De Robertis EM: Wnt signaling requires sequestration of glycogen synthase kinase 3 inside multivesicular endosomes. Cell 2010;143:1136-1148.

-33 Coghlan MP, Culbert AA, Cross DA, Corcoran SL, Yates JW, Pearce NJ, Rausch OL, Murphy GJ, Carter PS, Roxbee Cox L, Mills D, Brown MJ, Haigh D, Ward RW, Smith DG, Murray KJ, Reith AD, Holder JC: Selective small molecule inhibitors of glycogen synthase kinase-3 modulate glycogen metabolism and gene transcription. Chem Biol 2000;7:793-803.

34 Huang SM, Mishina YM, Liu S, Cheung A, Stegmeier F, Michaud GA, Charlat O, Wiellette E, Zhang Y, Wiessner S, Hild M, Shi X, Wilson CJ, Mickanin C, Myer V, Fazal A, Tomlinson R, Serluca F, Shao W, Cheng H, Shultz M, Rau C, Schirle M, Schlegl J, Ghidelli S, Fawell S, Lu C, Curtis D, Kirschner MW, Lengauer C, Finan PM, Tallarico JA, Bouwmeester T, Porter JA, Bauer A, Cong F: Tankyrase inhibition stabilizes axin and antagonizes wnt signalling. Nature 2009;461:614-620.

-35 Jiang W, Zhou L, Breyer B, Feng T, Cheng H, Haydon R, Ishikawa A, He TC: Tetracycline-regulated gene expression mediated by a novel chimeric repressor that recruits histone deacetylases in mammalian cells. J Biol Chem 2001;276:45168-45174.

-36 Su Y, Wagner ER, Luo Q, Huang J, Chen L, He BC, Zuo GW, Shi Q Zhang BQ Zhu G, Bi Y, Luo J, Luo X, Kim SH, Shen J, Rastegar F, Huang E, Gao Y, Gao JL, Yang K, Wietholt C, Li M, Qin J, Haydon RC, He TC, Luu $\mathrm{HH}$ : Insulin-like growth factor binding protein 5 suppresses tumor growth and metastasis of human osteosarcoma. Oncogene 2011;30:3907-3917.

-37 He BC, Chen L, Zuo GW, Zhang W, Bi Y, Huang J, Wang Y, Jiang W, Luo Q, Shi Q Zhang BQ Liu B, Lei X, Luo J, Luo X, Wagner ER, Kim SH, He CJ, Hu Y, Shen J, Zhou Q Rastegar F, Deng ZL, Luu HH, He TC, Haydon RC: Synergistic antitumor effect of the activated ppargamma and retinoid receptors on human osteosarcoma. Clin Cancer Res 2010;16:2235-2245.

-38 He BC, Gao JL, Zhang BQ, Luo Q, Shi Q, Kim SH, Huang E, Gao Y, Yang K, Wagner ER, Wang L, Tang N, Luo J, Liu X, Li M, Bi Y, Shen J, Luther G, Hu N, Zhou Q Luu HH, Haydon RC, Zhao Y, He TC: Tetrandrine inhibits wnt/beta-catenin signaling and suppresses tumor growth of human colorectal cancer. Mol Pharmacol 2011;79:211-219.

-39 Huang E, Bi Y, Jiang W, Luo X, Yang K, Gao JL, Gao Y, Luo Q Shi Q, Kim SH, Liu X, Li M, Hu N, Liu H, Cui J, Zhang W, Li R, Chen X, Shen J, Kong Y, Zhang J, Wang J, Luo J, He BC, Wang H, Reid RR, Luu HH, Haydon $\mathrm{RC}$, Yang L, He TC: Conditionally immortalized mouse embryonic fibroblasts retain proliferative activity without compromising multipotent differentiation potential. PloS One 2012;7:e32428.

-40 Huang E, Zhu G, Jiang W, Yang K, Gao Y, Luo Q, Gao JL, Kim SH, Liu X, Li M, Shi Q, Hu N, Wang L, Liu H, Cui J, Zhang W, Li R, Chen X, Kong YH, Zhang J, Wang J, Shen J, Bi Y, Statz J, He BC, Luo J, Wang H, Xiong F, Luu HH, Haydon RC, Yang L, He TC: Growth hormone synergizes with bmp9 in osteogenic differentiation by activating the jak/stat/igf1 pathway in murine multilineage cells. J Bone Miner Res 2012;27:1566-1575.

-41 Yang K, Chen J, Jiang W, Huang E, Cui J, Kim SH, Hu N, Liu H, Zhang W, Li R, Chen X, Kong Y, Zhang J, Wang J, Wang L, Shen J, Luu HH, Haydon RC, Lian X, Yang T, He TC: Conditional immortalization establishes a repertoire of mouse melanocyte progenitors with distinct melanogenic differentiation potential. J Invest Dermatol 2012;132:2479-2483. 


\section{Cellular Physiology and Biochemistry}

Cell Physiol Biochem 2013;32:1187-1199

\begin{tabular}{l|l}
\hline DOI: $10.1159 / 000354518$ & (C) 2013 S. Karger AG, Basel
\end{tabular} www.karger.com/cpb

Kong et al.: Degradation Mediated by GSK3 $\beta$ Sites of $\beta$-Catenin

42 Hu N, Jiang D, Huang E, Liu X, Li R, Liang X, Kim SH, Chen X, Gao JL, Zhang H, Zhang W, Kong YH, Zhang J, Wang J, Shui W, Luo X, Liu B, Cui J, Rogers MR, Shen J, Zhao C, Wang N, Wu N, Luu HH, Haydon RC, He TC, Huang W: Bmp9-regulated angiogenic signaling plays an important role in the osteogenic differentiation of mesenchymal progenitor cells. J Cell Sci 2013;126:532-541.

-43 He TC, Zhou S, da Costa LT, Yu J, Kinzler KW, Vogelstein B: A simplified system for generating recombinant adenoviruses. Proc Natl Acad Sci U S A 1998;95:2509-2514.

-44 Luo Q, Kang Q Si W, Jiang W, Park JK, Peng Y, Li X, Luu HH, Luo J, Montag AG, Haydon RC, He TC: Connective tissue growth factor (ctgf) is regulated by wnt and bone morphogenetic proteins signaling in osteoblast differentiation of mesenchymal stem cells. J Biol Chem 2004;279:55958-55968.

-45 Si W, Kang Q, Luu HH, Park JK, Luo Q Song WX, Jiang W, Luo X, Li X, Yin H, Montag AG, Haydon RC, He TC: Ccn1/cyr61 is regulated by the canonical wnt signal and plays an important role in wnt3a-induced osteoblast differentiation of mesenchymal stem cells. Mol Cell Biol 2006;26:2955-2964.

-46 Luo J, Deng ZL, Luo X, Tang N, Song WX, Chen J, Sharff KA, Luu HH, Haydon RC, Kinzler KW, Vogelstein B, He TC: A protocol for rapid generation of recombinant adenoviruses using the adeasy system. Nat Protoc 2007;2:1236-1247.

47 Tang N, Song WX, Luo J, Luo X, Chen J, Sharff KA, Bi Y, He BC, Huang JY, Zhu GH, Su YX, Jiang W, Tang M, He Y, Wang Y, Chen L, Zuo GW, Shen J, Pan X, Reid RR, Luu HH, Haydon RC, He TC: Bmp9-induced osteogenic differentiation of mesenchymal progenitors requires functional canonical wnt/beta-catenin signaling. J Cell Mol Med 2009;13:2448-2464.

-48 Bi Y, Huang J, He Y, Zhu GH, Su Y, He BC, Luo J, Wang Y, Kang Q Luo Q, Chen L, Zuo GW, Jiang W, Liu B, Shi Q Tang M, Zhang BQ Weng Y, Huang A, Zhou L, Feng T, Luu HH, Haydon RC, He TC, Tang N: Wnt antagonist sfrp3 inhibits the differentiation of mouse hepatic progenitor cells. J Cell Biochem 2009;108:295-303.

-49 Zhou L, An N, Jiang W, Haydon R, Cheng H, Zhou Q, Breyer B, Feng T, He TC: Fluorescence-based functional assay for wnt/beta-catenin signaling activity. Biotechniques 2002;33:1126-1128, 1130, 1132 passim.

-50 Shui W, Yin L, Luo J, Li R, Zhang W, Zhang J, Huang W, Hu N, Liang X, Deng ZL, Hu Z, Shi LL, Luu HH, Haydon RC, He TC, Ho SH: Characterization of chondrocyte scaffold carriers for cell-based gene therapy in articular cartilage repair. J Biomed Mater Res A 2013;101:3542-3550.

51 Bullions LC, Levine AJ: The role of beta-catenin in cell adhesion, signal transduction, and cancer. Curr Opin Oncol 1998;10:81-87.

-52 Stambolic V, Ruel L, Woodgett JR: Lithium inhibits glycogen synthase kinase-3 activity and mimics wingless signalling in intact cells. Curr Biol 1996;6:1664-1668. Erratum Curr Biol 1997;7:196.

-53 Klein PS, Melton DA: A molecular mechanism for the effect of lithium on development. Proc Natl Acad Sci USA 1996;93:8455-8459.

54 Morin PJ: Beta-catenin signaling and cancer. Bioessays 1999;21:1021-1030.

55 Rimm DL, Caca K, Hu G, Harrison FB, Fearon ER: Frequent nuclear/cytoplasmic localization of beta-catenin without exon 3 mutations in malignant melanoma. Am J Pathol 1999;154:325-329.

-56 Haydon RC, Deyrup A, Ishikawa A, Heck R, Jiang W, Zhou L, Feng T, King D, Cheng H, Breyer B, Peabody T, Simon MA, Montag AG, He TC: Cytoplasmic and/or nuclear accumulation of the beta-catenin protein is a frequent event in human osteosarcoma. Int J Cancer 2002;102:338-342. 